\title{
NASAL IRRIGATION AND GARGLING WITH HYPERTONIC SALINE TO PREVENT TRANSMISSION OF SARS-COV-2 TO CARE HOME RESIDENTS - A FEASIBILITY CLUSTER TRIAL
}

\author{
R.M. BUCHANAN ${ }^{1,2}$, K. IBRAHIM ${ }^{1,2}$, H.C. ROBERTS ${ }^{1,2}$, B. STUART ${ }^{3}$, F. WEBLEY ${ }^{3}$, Z. EMINTON ${ }^{3}$, \\ D. BALL ${ }^{3}$, F. CHINNERY ${ }^{3}$, J. PARKES ${ }^{1,2}$, J. WYATT $^{1}$, T. DANIELS ${ }^{4}$

\begin{abstract}
1. Faculty of Medicine, University of Southampton, Southampton, Hampshire, United Kingdom; 2. NIHR Applied Research Collaboration Wessex, University of Southampton, Hampshire, United Kingdom; 3. Southampton Clinical Trials Unit, University of Southampton, Southampton, Hampshire, United Kingdom; 4. Respiratory Department, University Ryan M Buchanan, University of Southampton, Room AC22, C level, South Academic Block, University Hospital Southampton, Tremona Road, Southampton, Hampshire SO166YD, ryan.buchanan@soton.ac.uk
\end{abstract} \\ Hospital Southampton, Southampton, Hampshire, United Kingdom \& University of Southampton Respiratory Biomedical Research Centre, United Kingdom. Corresponding author:
}

\begin{abstract}
Hypertonic saline nasal irrigation and gargling (HSNIG) has the potential to reduce COVID 19 transmission. We present a pilot cluster randomised controlled trial to assess the feasibility and acceptability of a future trial to test the effectiveness of HSNIG in care homes (CHs). Staff in the intervention CHs were invited to perform HSNIG whereas control $\mathrm{CHs}$ carried on with their routine protection procedures. The acceptability of HSNIG was explored via interviews and online surveys. Seven $(21 \%)$ of contacted CHs participated but following randomisation three (43\%) dropped out leaving two intervention $\mathrm{CHs}$ and two control CHs. Facilitators to uptake of HSNIG included motivated 'champions' and integration into routines. Barriers included a lack of ownership and perceptions of reduced risk from COVID-19. Recruiting and retaining CHs in this study was challenging. Although HSNIG was reported to be safe and acceptable by staff, further work is required to quantify and optimise its acceptability.
\end{abstract}

Key words: COVID-19, nasal irrigation, gargling, hypertonic saline, care home, Sars-CoV-2; HSNIG.

\section{Introduction}

COVID-19 has a high mortality rate in older people (1). There have been many devastating outbreaks in care homes (CHs) (2). In England there were over 12000 deaths in CHs in the 1 st wave of the pandemic and $\mathrm{CH}$ associated fatalities accounted for over a third of total deaths in the USA in the same time-frame $(3,4)$.

It is recognised that COVID-19 is carried in the nasal passages of asymptomatic individuals (5-8). Nasal irrigation with salty water is already used as a simple and cheap treatment for sinusitis and hypertonic saline and has been shown to have anti-microbial (8) and anti-viral properties (9). A trial of regular hypertonic saline nasal irrigation rinse and mouth gargle (HSNIG) for viral upper respiratory tract infections has shown a reduction in transmission of symptoms to close contacts (8). Importantly, this study also recorded a decline in the viral load of corona viruses indicating the potential utility of HSNIG in reducing COVID-19 transmission (10).

The effectiveness of HSNIG by $\mathrm{CH}$ staff at preventing COVID-19 in residents has not been investigated. However, before designing an effectiveness trial of HSNIG by $\mathrm{CH}$ staff to prevent COVID-19 in residents it is necessary to pilot the study design and the HSNIG intervention. Therefore the aim of this study was to assess the feasibility of recruiting and randomising $\mathrm{CHs}$ and the acceptability of HSING by $\mathrm{CH}$ staff.

\section{Methods}

\section{Study design and setting}

The study was a pilot cluster-RCT of daily HSNIG for $\mathrm{CH}$ staff. Whole $\mathrm{CH}$ s were randomised 1:1 to either HSNIG by staff, or usual infection control/hygiene practice. To meet our study objectives we aimed to recruit eight $\mathrm{CHs}$.

All CHs in Hampshire (United Kingdom) were potentially eligible to participate in the study. Exclusion criteria included CHs where HSNIG was already part of hygiene policy or those with $\geq 50 \%$ of agency staff. $\mathrm{CH}$ managers were contacted by phone; those who expressed interest were emailed an information sheet and contacted to ask if they wanted to participate. The Southampton Clinical Trials Unit (CTU) randomised $\mathrm{CHs}$ to intervention or control immediately after recruitment. The study had ethical approval from a UK National Research Ethics Committee (20/WA/0162). The study protocol was registered online: http://www.anzctr.org.au/Trial/ Registration/TrialReview. aspx ?id=379905\&isReview=true.

\section{Intervention}

Staff were asked to perform HSNIG at the beginning of each shift and up to twice more mid-shift for 12 weeks. The $\mathrm{CH}$ manager was asked to nominate an enthusiastic champion to lead training and implementation. A video produced by the research team was sent to the managers and the nominated champions (see link-https://www.youtube.com/watch?v=__QSLlGWps) that demonstrated how to perform HSNIG. The HSNIG equipment was a plastic $60 \mathrm{ml}$ galley pot, $1.5 \mathrm{~g}$ of sea 


\section{NASAL IRRIGATION AND GARGLING WITH HYPERTONIC SALINE}

salt in two sachets and a plastic stirrer (cost 0.16 GBP). Staff members had to make up the solution themselves and could opt out of performing HSNIG at any time.

\section{Control care homes}

All CHs were asked to continue with existing infection control precautions including hand washing and protection equipment as per $\mathrm{CH}$ policy. Control $\mathrm{CHs}$ were not asked to perform HSNIG or given the training videos.

\section{Data collection and analysis}

HSNIG champions were asked about engagement with HSNIG training and the number of staff rinsing during shifts via weekly online surveys. A purposive sample of staff, managers and champions in the intervention $\mathrm{CHs}$ (including those which withdrew and continued) were also invited for a telephone interview to explore their views and experiences with the study. Interviews transcripts were anonymised and analysed using thematic analysis with constant comparison (11).

\section{Results}

\section{Recruitment and randomisation}

Thirty-three CHs were approached and seven agreed to participate (Figure 1). Twenty-six CHs declined to participate in the study: six (23\%) declined by 'head office' without further explanation, three (12\%) declined because of an active outbreak of COVID-19, three (12\%) declined because they were 'too busy' and one (4\%) declined to participate because the idea of HSNIG was unacceptable to staff members.

Seven CHs were randomised. One dropped out immediately after allocation to 'control' because the manager found this unacceptable and wanted to use HSNIG. Two of the four CHs in the intervention arm never implemented HSNIG because one was overwhelmed and the other felt the pandemic had passed (Figure 1). Therefore, four CHs completed the study (dropout rate $=43 \%$ ): two in the control arm and two in the intervention arm.

\section{Acceptabilty of the HSNIG}

The online 'champions' weekly survey from the two intervention $\mathrm{CHs}$ that implemented HSNIG were received for four weeks (weeks 1 to 4) of the intended 12-week study period. The champions reported that the proportion of staff administering HSNIG 2-3 times per shift varied from $40 \%$ to $100 \%$ during these weeks. We received no survey returns after week 4 . However, the qualitative interviews indicated that staff carried on performing the procedure until the end of 12 weeks.

Six telephone interviews were conducted with two managers, two champions and two staff members from three out of the four $\mathrm{CHs}$ that were randomised to the intervention. These included two CHs that implemented HSNIG and one that withdrew. Interviews took place 6-12 weeks following randomisation and were on average 20minutes long.

Figure 1

CONSORT diagram showing care home recruitment and retention in the study

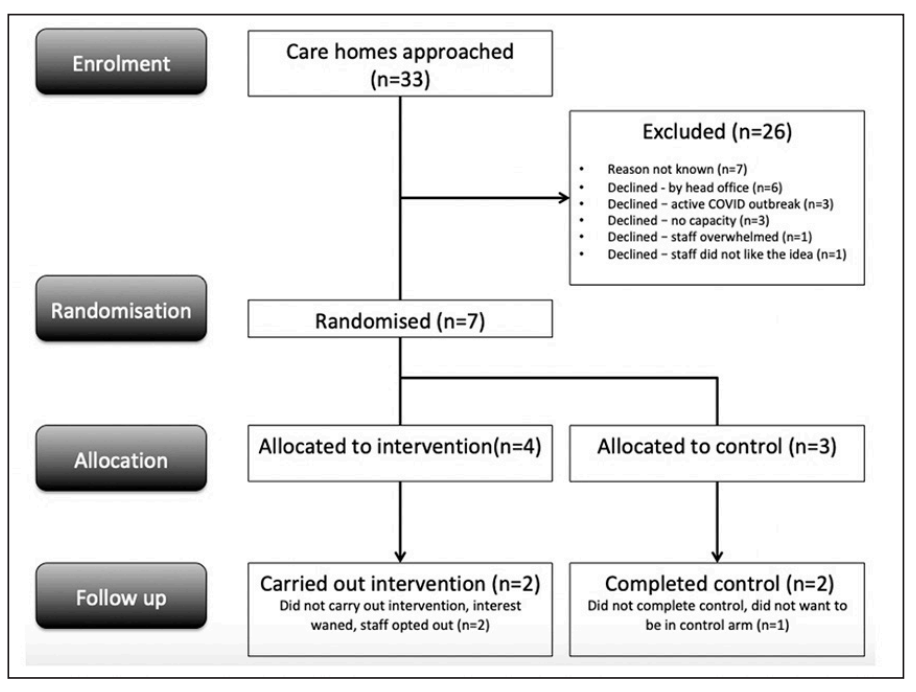

Barriers and facilitators for HSNIG implementation in CHs are summarised with direct quotes from participants in Table 1. A number of facilitators to uptake of the HSNIG were reported including enthusiastic champions and motivated staff. Strong leadership and a shared commitment from managers and champions as well as the integration of HSNIG into daily routines also facilitated implementation. Easily accessible information and training materials as well as the simplicity of the intervention were additional facilitators. All interviewees were satisfied with the training materials and found them understandable. Participants reported that group training with champions was preferable as it promoted a shared commitment by staff and that having someone to watch them was reassuring. No staff members reported adverse events from HSNIG and most participants found the intervention easy, quick and noninvasive. Some described finding it easier the more they did it.

A number of barriers were reported including a lack of staff motivation. This was due to staff already feeling that COVID19 was less a threat, or due to negative test results and feeling they were doing enough to prevent the virus from coming to their home. Perceived lack of proven benefits from the HSNIG and the view that nothing can stop COVID-19 from spreading contributed to staff lack of motivation. Lack of ownership by managers and champions was also a reported barrier that influenced staff motivation to implement HSNIG. Interviewees also mentioned how time constraints and workload during the pandemic and the fact that they had to implement other infection control procedures hindered them from trying the intervention. Some interviewees also reported that HSNIG was an unpleasant experience that made some feel sick and unwilling to carry on with it. 
Table 1

Quotes from qualitative interviews highlighting important barriers and facilitators for the uptake of hypertonic saline nasal irrigation and gargling by care home staff

Facilitators
Enthusiastic champions
The first time they done the Rinses (name, champion) um, was with them when
they done it to make sure that they were doing it properly and there was no
problems or discussed it with them (CH2)
Strong leadership
I think sometimes, as Managers, or um, Deputy Manager, I think it's really, er,
if you do it yourself and you sort of put it across as positively as you can and
that's how it comes back the other way.... think if it's from the top it works
better. It works better if basically everybody is doing it not just it's handed
across to somebody else to do .. it's from the top and that. They see you doing
it and that's the thing.(CH3)

Motvation (fighting the virus, appreciating potential benefits from intervention) Yeah, they're all up for things at the moment. Cos of the state of outside with COVID and all that, I mean everyone wants to try something. You know, to help in some way so they were all ready to do it. (CH3)

Accessible information and training materials

They were really, yeah they were really good. Um, I think because I'm just, out of pure nosiness, um I was sort of, you know, using the other um, to have a look around but they gave us the best um, training tools they could have. You couldn't have done it any other way and I think, you know, people were up. (CH5)

\section{Shared commitment}

We've got a bathroom downstairs that they were using, and they were choosing. So that one would be doing it to show the next person and it would just be an ongoing training (so it). It really took, yeah. they took it as kind of a, group, you know a group commitment, yeah. (CH5)

Integration in to daily routines

When they first got changed, before coming onto the floor, they would do it. And then coming to handover. Um, and then same again finish handover... getting into that habit and routine... $(\mathrm{CH} 2)$

\section{Simplicity of the intervention}

I think it's easy enough and its quick enough to do. Um, and it is a massive intervention which is obviously brilliant isn't it?(CH2)

Yes, I think they were, they were, I mean not everybody liked the taste of the salty water. But I think the benefits and the, the chance to, for them to make a difference, stop it in some way then that's what they're there for really $(\mathrm{CH} 3)$

\section{Barriers}

lack of ownership by managers and champions

I mean, I think that is probably something you need to discuss much more with (the $\mathrm{CH}$ champion) cos obviously that's not, you know, that's not a decision that I could make. Um, So, (champion) the Deputy Manager she would be the one that would actually make that decision $(\mathrm{CH} 4)$

\section{lack of staff motivation and engagement}

Initially um, there were quite a few people that wanted to give it a go, but.. they've had time to think about it I think they feel that COVID was less of a threat... I think the fear factor has decreased.... (CH1)

I think people dropped out even more because we were all tested. You got tested for it and all of us came back negative.(CH4)

I mean staff morale's a big thing so if one was to do it, all of the others will follow suit, well some might change their mind. You know, it is a bit like that and um, and that's, I don't know (CH1)

You know, we had a chat about it. Um, but obviously quite a few people dropped out as it kind of went on. They weren't not as concerned about COVID $(\mathrm{CH} 4)$

obviously, as far as I'm aware the infection spread whether it would help, or not help it. If you get what I mean. But as far as I'm aware with COVID there's nothing, at the moment, that's gonna stop it. If you're gonna get it, you're gonna get it. I know the Antibodies Tests are coming back as negative, you know, with that so, but I just don't know. I'm not sure whether they say there's going to be a cure $(\mathrm{CH} 4)$

Time constraints and workload

it has been obviously incredibly busy this time, so Residents obviously are missing their families, you know, so we're not just Carers for the Residents at the moment, we are, you know, family members as well... (CH4)

Intolerance of the intervention

Yeah, yeah. We did have, um, a very small group that said, 'I can't do this'. (giggle) .. I think there was about 5 people that just absolutely refused, you know, it made them sick., yeah, they were just, 'I can't have that in my mouth'. A couple of people decided they'd rather just do their noses, but they couldn't do their mouths. Um, but yeah (CH5)

\section{Discussion}

We have shown two important positive findings. Firstly, it is feasible to recruit $\mathrm{CHs}$ for a cluster RCT of HSNIG by $\mathrm{CH}$ staff and secondly, whilst some staff members can willingly and safely perform HSNIG, its widespread implementation is challenging. Specifically, randomisation to standard care was unacceptable for one $\mathrm{CH}$ and retention of $\mathrm{CHs}$ in the intervention group proved challenging. Furthermore, we highlight significant difficulties with remote data collection to ascertain the acceptability of HSNIG in CHs during a pandemic.

Other teams have described some of the challenges we have encountered in $\mathrm{CH}$ research. Gaining necessary regulatory approvals takes time - particularly for clinical trials (13), recruitment can be problematic (14), and taking consent from participants is challenging (15). Based on our experience in this study we would argue that research in the 'COVID-era' with limited access to the $\mathrm{CHs}$ by any visitors, including researchers, is a new obstacle.

Limitations of this study affect the reliability of our findings. Our sample of interview participants was small and the majority were from $\mathrm{CHs}$ that had successfully implemented HSNIG for a period. This may have led to an overly positive assessment of the HSNIG procedure. Even within these $\mathrm{CHs}$ 


\section{NASAL IRRIGATION AND GARGLING WITH HYPERTONIC SALINE}

we were reliant on participants contacting us for an interview and it is likely these willing individuals were more engaged with the study.

Despite these limitations, our findings are worthy of consideration when designing a future effectiveness trial. An alternative design such as a stepped-wedge (12) trial should be considered, and whilst managerial support and the use of champions are likely to help, it is likely that researchers need to be physically present in the $\mathrm{CH}$ setting to support implementation of HSNIG and collect clinical outcome data collection.

HSNIG has the potential to reduce transmission of COVID19 to $\mathrm{CH}$ residents and other respiratory viruses. However, the acceptability of HSNIG by $\mathrm{CH}$ staff needs further investigation and acceptable, reliable and safe approaches to collect quantitative data from $\mathrm{CHs}$ during the COVID pandemic need to be considered.

Acknowledgements: The research team are very grateful to the care homes and staff members who participated in the study. We are also grateful to our patient and public involvement representatives who gave up their time to support the design and implementation of the study. The study was sponsored by the University of Southampton. The opinions expressed in this document are those of the authors. The sponsor had no role in the design, methods, data collection, analysis and preparation of this paper.

Funding Source: This research is funded as part of a block grant by the National Institute for Health Research (NIHR) Applied Research Collaboration Wessex. The views expressed are those of the authors and not necessarily those of the NHS, the NIHR, or the Department of Health. RB is supported by the NIHR Academic Clinical Lecturer scheme. KI, HCR and JP receive support from the NIHR Applied Research Collaboration (ARC) Wessex. HCR receives support from the NIHR Southampton Biomedical Research Centre.

Conflict of Interest: All authors declare no conflicts of interest.

Ethical standards: All aspects of the study was approved by the National Health Service for England Research Ethics Committee (Reference number 20/WA/0162) and the University of Southampton ethics committee. Care home workers were invited to conduct the hypertonic saline nasal irrigation and gargling (HSNIG) procedure by care home managers and champions. They were free to opt out at any time. Care home staff who participated in the telephone interviews gave verbal consent. Written consent was not taken to minimise physical contact between researchers and the care home environment - care homes were in 'lock down' during the study. A record of the verbal consent procedure was recorded on the trust file on the secure University of Southampton server.

\section{References}

1. Zhou F, Yu T, Du R, et al. Clinical course and risk factors for mortality of adult inpatients with COVID-19 in Wuhan, China: a retrospective cohort study. Lancet (London, England). 2020;395(10229):1054-1062.

2. Coronavirus: Care home loses "number" of residents to disease - BBC News. https:// www.bbc.co.uk/news/uk-england-bristol-52263782. Accessed April 21, 2020.

3. More Than One-Third of U.S. Coronavirus Deaths Are Linked to Nursing Homes - The New York Times. https://www.nytimes.com/interactive/2020/us/coronavirusnursing-homes.html. Accessed February 22, 2021.

4. Deaths involving COVID-19 in the care sector, England and Wales-Office for National Statistics. https://www.ons.gov.uk/ peoplepopulationandcommunity/birthsdeathsandmarriages/deaths/articles/ deathsinvolvingcovid19inthecaresectorenglandandwales/deathsoccurringupto1may2 020andregisteredupto9may2020provisional\#deaths-involving-covid-19-among-carehome-res. Accessed July 1, 2020.

5. Li R, Pei S, Chen B, et al. Substantial undocumented infection facilitates the rapid dissemination of novel coronavirus (SARS-CoV2). Science. March 2020.

6. Wölfel R, Corman VM, Guggemos W, et al. Virological assessment of hospitalized patients with COVID-2019. Nature. April 2020:1-10.

7. Arons MM, Hatfield KM, Reddy SC, et al. Presymptomatic SARS-CoV-2 Infections and Transmission in a Skilled Nursing Facility. N Engl J Med. April 2020:NEJMoa2008457. doi:10.1056/NEJMoa2008457

8. Hou YJ, Okuda K, Edwards CE, et al. SARS-CoV-2 Reverse Genetics Reveals a Variable Infection Gradient in the Respiratory Tract. Cell. May 2020.

9. Ramalingam S, Cai B, Wong J, et al. Antiviral innate immune response in nonmyeloid cells is augmented by chloride ions via an increase in intracellular hypochlorous acid levels. Sci Rep. 2018;8(1):13630

10. Ramalingam S, Graham C, Dove J, Morrice L, Sheikh A. A pilot, open labelled, randomised controlled trial of hypertonic saline nasal irrigation and gargling for the common cold. Sci Rep. 2019;9(1):1015.

11. Braun V, Clarke V. What can "thematic analysis" offer health and wellbeing researchers? Int J Qual Stud Health Well-being. 2014;9:26152.

12. Hemming K, Haines TP, Chilton PJ, Girling AJ, Lilford RJ. The stepped wedge cluster randomised trial: rationale, design, analysis, and reporting. BMJ. 2015;350:h391.

13. Shepherd V, Nuttall J, Hood K, Butler CC. Setting up a clinical trial in care homes: challenges encountered and recommendations for future research practice. BMC Res Notes. 2015;8(1):306.

14. Ellwood A, Airlie J, Cicero R, et al. Recruiting care homes to a randomised controlled trial. Trials. 2018;19(1):535.

15. Hall S, Longhurst S, Higginson IJ. Challenges to conducting research with older people living in nursing homes. BMC Geriatr. 2009;9(1):38. 